\title{
Sea-Urchin-Like ZnO Nanoparticle Film for Dye-Sensitized Solar Cells
}

\author{
Cheng-Wen Ma, Chia-Ming Chang, Po-Cheng Huang, and Yao-Joe Yang \\ Department of Mechanical Engineering, National Taiwan University, No. 1, Section 4, Roosevelt Road, Taipei 10617, Taiwan \\ Correspondence should be addressed to Yao-Joe Yang; yjy@ntu.edu.tw
}

Received 19 May 2015; Accepted 14 July 2015

Academic Editor: Tapan Desai

Copyright (c) 2015 Cheng-Wen Ma et al. This is an open access article distributed under the Creative Commons Attribution License, which permits unrestricted use, distribution, and reproduction in any medium, provided the original work is properly cited.

\begin{abstract}
We present novel sea-urchin-like $\mathrm{ZnO}$ nanoparticles synthesized using a chemical solution method. Solution approaches to synthesizing $\mathrm{ZnO}$ nanostructures have several advantages including low growth temperatures and high potential for scaling up. We investigated the influence of reaction times on the thickness and morphology of sea-urchin-like ZnO nanoparticles, and XRD patterns show strong intensity in every direction. Dye-sensitized solar cells (DSSCs) were developed using the synthesized ZnO nanostructures as photoanodes. The DSSCs comprised a fluorine-doped tin oxide (FTO) glass with dense ZnO nanostructures as the working electrode, a platinized FTO glass as the counter electrode, N719-based dye, and I-/I3-liquid electrolyte. The DSSC fabricated using such nanostructures yielded a high power conversion efficiency of $1.16 \%$ with an incident photo-to-current efficiency (IPCE) as high as 15.32\%. Electrochemical impedance spectroscopy was applied to investigate the characteristics of DSSCs. An improvement in the electron transport in the $\mathrm{ZnO}$ photoanode was also observed.
\end{abstract}

\section{Introduction}

Dye-sensitized solar cells (DSSCs) provide efficient solarenergy conversion and have attracted substantial attention over the past decade because of their structural flexibility, low cost, and ease of fabrication [1-3]. In general, DSSCs comprise a porous $\mathrm{TiO}_{2}$ nanoparticle photoanode [4-6]. Researchers in many recent studies have focused on improving performance through developing new substitutes for porous $\mathrm{TiO}_{2}$ nanoparticle films for use in photoanodes, such as the $\mathrm{TiO}_{2}$-nanowire type $[7,8]$ and $\mathrm{TiO}_{2}$-nanotube type $[9,10]$. However, a recombination problem usually occurs in $\mathrm{TiO}_{2}$ nanocrystals because of the lack of a depletion layer on the $\mathrm{TiO}_{2}$ surface. The severity of the recombination problem increases with the $\mathrm{TiO}_{2}$ photoanode film thickness [11].

In recent years, $\mathrm{ZnO}$-based materials have been widely studied for use as photoanodes for DSSC devices [12]. Although $\mathrm{ZnO}$ has a similar energy level of the conduction band as that of $\mathrm{TiO}_{2}$, the $\mathrm{ZnO}$-based DSSCs in general give lower efficiency as compared to $\mathrm{TiO}_{2}$-based DSSCs. One of the reasons is caused by the precipitation of the sensitizing dye with $\mathrm{Zn}$ cations for the $\mathrm{ZnO}$-based DSSCs. However, it is relatively difficult to grow $\mathrm{TiO}_{2}$ films on a substrate with controlled structure, which in turn limits the development of $\mathrm{TiO}_{2}$-based DSSCs. Furthermore, in terms of material characteristics, $\mathrm{ZnO}$ has a few advantages over $\mathrm{TiO}_{2}$, such as higher electronic mobility and more flexibility in high-area film morphologies. Therefore, $\mathrm{ZnO}$ is considered as one of the promising alternatives for $\mathrm{TiO}_{2}$ as the core material of DSSCs.

Numerous types of $\mathrm{ZnO}$ nanostructures have been proposed for application in DSSCs. For example, Law et al. [13] proposed a DSSC including a dense array of oriented $\mathrm{ZnO}$ nanowires as a photoanode material with a $1.51 \%$ conversion efficiency. In [14], $\mathrm{ZnO}$ nanotube photoanodes templated using anodic aluminum oxide for use in DSSCs were reported. Anodic aluminum oxide templating and atomic layer deposition were employed to yield oriented arrays of electrically interconnected nanotubes. In addition, in [15], $\mathrm{ZnO}$ nanoforest photoanodes, which effectively increased the power conversion efficiency to approximately $2.63 \%$, were introduced. The efficiency increase is due to the substantially enhanced surface area and reduced charge recombination. Kakiuchi et al. [16] proposed a DSSC with a $\mathrm{ZnO}$ nanosheet structure synthesized using $\mathrm{Zn}\left(\mathrm{NO}_{3}\right)_{2}$ and $\left(\mathrm{NH}_{2}\right)_{2} \mathrm{CO}$, 


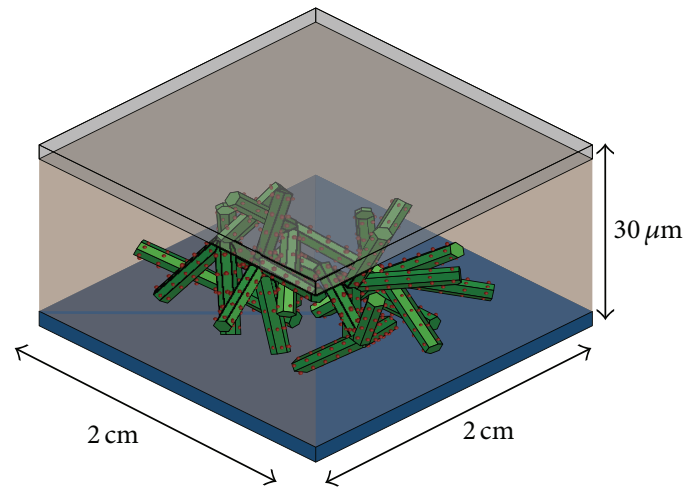

(a)

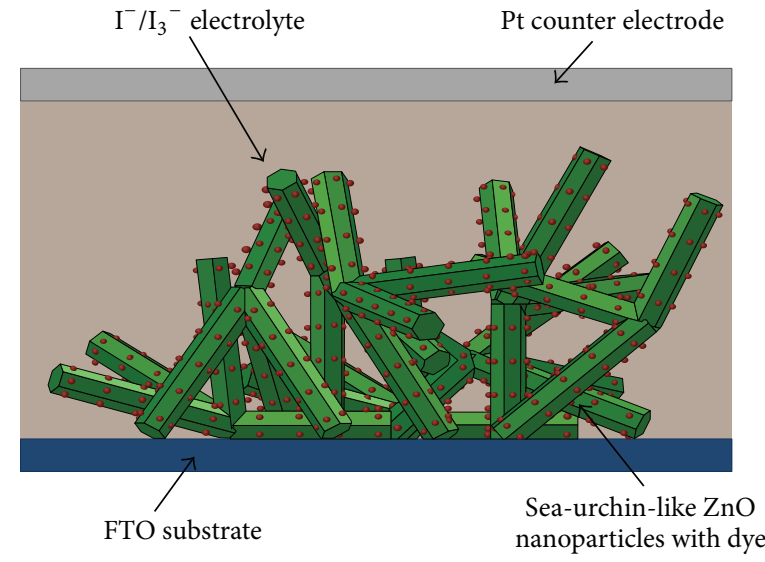

(b)

FIgURE 1: (a) Schematic of the dye-sensitized solar cell based on sea-urchin-like ZnO nanoparticles. (b) Schematic of the side view.

achieving a conversion efficiency of $3.3 \%$. In [17], $\mathrm{ZnO}$ nanoarchitecture fabricated on a plastic substrate by using a facile room-temperature chemical-bath deposition method was presented. A notable efficiency of $5.24 \%$ was simply achieved using a low crystallization temperature and the anisotropic growth of $\mathrm{ZnO}$. In addition, the synthesis of a DSSC with a sponge-like $\mathrm{ZnO}$ nanostructure was reported in [18]. By using a polymer gel electrolyte to stabilize the dye/ZnO/electrolyte interface, an improvement of the electron injection efficiency, photovoltaic conversion efficiencies, and the long-term durability of ZnO-based DSSCs was achieved.

In this work, we propose a DSSC in which the photoanode is based on sea-urchin-like $\mathrm{ZnO}$ nanoparticles that can be easily formed through chemical solution synthesis. We also studied the effects of nanoparticle morphologies on different synthesis parameters. In addition, the sea-urchin-like structures may potentially enhance the surface area to improve dye absorbance. Because of the branched characteristic of the seaurchin-like structures, they can easily form strong conductive networks.

The remainder of this paper is organized as follows. Section 2 describes the synthesis, photoanode preparation, and DSSC fabrication. The measurement results are presented in Section 3. Conclusions are provided in Section 4.

\section{Synthesis of Nanoparticles}

Figure 1 shows a schematic of the proposed DSSC. From the lower to the upper layer, the cell comprises a fluorinedoped tin oxide (FTO) transparent conductive glass with a $\mathrm{ZnO}$ photoanode and platinized counter electrode. Organic dye molecules are absorbed on the photoanode, with the electrolyte positioned between the electrodes. This study proposes using novel sea-urchin-like $\mathrm{ZnO}$ nanoparticles as a photoanode material according to the following fabrication process.

The chemical solution method [19] was used to synthesize the sea-urchin-like $\mathrm{ZnO}$ nanoparticle structure. First, a room-temperature solution was prepared. The solution was composed of $75 \mathrm{mM}$ zinc nitrate hexahydrate, $25 \mathrm{mM}$ HMTA, $5 \mathrm{mM}$ PEI, and $0.80 \mathrm{M}$ ammonium hydroxide. The reaction solution was heated in two steps [20]. In a container, the solution was first heated to $85^{\circ} \mathrm{C}$ in a water bath while covered by a watch glass. After $15 \mathrm{~min}$, the glass was removed, exposing the solution to open air for another $15 \mathrm{~min}$. The nondirectional $\mathrm{ZnO}$ nanostructures (sea-urchin-like $\mathrm{ZnO}$ nanoparticles) formed on the bottom of the container. Next, the container was covered with the watch glass to prevent further solution evaporation. The deposited $\mathrm{ZnO}$ structure continued to grow. Finally, the sea-urchin-like $\mathrm{ZnO}$ nanoparticles were deposited on the top of the FTO electrode.

After the synthesis reaction, the FTO covered with a sea-urchin-like $\mathrm{ZnO}$ nanoparticle film (the photoanode) was dried in $\mathrm{N}_{2}$ for a few minutes and then heated in a tube furnace at $400^{\circ} \mathrm{C}$ for $30 \mathrm{~min}$. The heating process enhanced the mechanical strength of the $\mathrm{ZnO}$ film and the adhesion between the film and the FTO substrate.

The FTO substrate with the sea-urchin-like $\mathrm{ZnO}$ nanoparticles (the fabricated photoanode) was immersed in an ethanol solution of $\mathrm{N} 719$ dye at $50^{\circ} \mathrm{C}$ for $2 \mathrm{~h}$. After fully absorbing the dye molecules, the FTO substrate was washed with ethanol and then air dried. A FTO glass deposited with a platinum film served as the counter electrode. The photoanode and counter electrode were then sandwiched using Surlyn E185SB (Dupont). A liquid electrolyte was then injected into the cavity of the photoanode and counter electrode. The electrolyte contains $0.5 \mathrm{M} \mathrm{LiI}, 50 \mathrm{mM} \mathrm{I}_{2}$, and $0.5 \mathrm{M}$ 4-tert-butylpyridine in a 3-methoxypropionitrile solvent [13].

\section{Results and Discussion}

3.1. Morphology and Structure Characterization. Figures 2(a) and 2(b) show the SEM images of the sea-urchin-like $\mathrm{ZnO}$ nanoparticles with various deposition times. Figure 2(c) illustrates the detailed structural morphologies, indicating that the longer the deposition time, the longer the branch length of the $\mathrm{ZnO}$ nanoparticles because of the increased reaction time, 


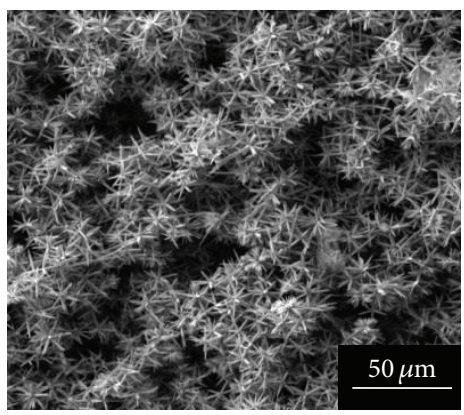

(a)

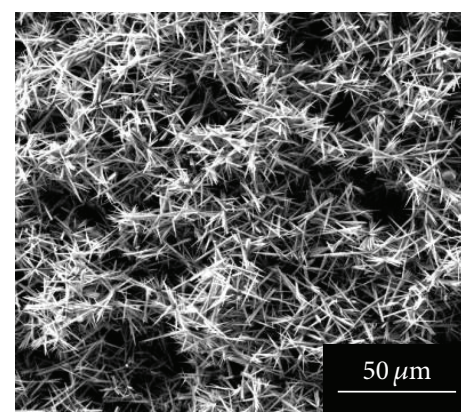

(b)

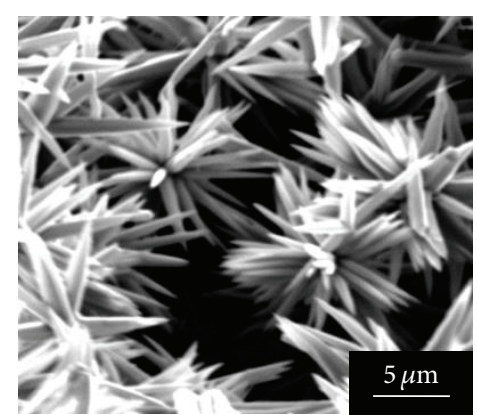

(c)

FIgURE 2: SEM pictures of sea-urchin-like ZnO nanoparticles after (a) $2 \mathrm{hr}$ deposition and (b) $8 \mathrm{hr}$ deposition. (c) The detailed structure morphology of the nanoparticle ( $8 \mathrm{hr}$ deposition).

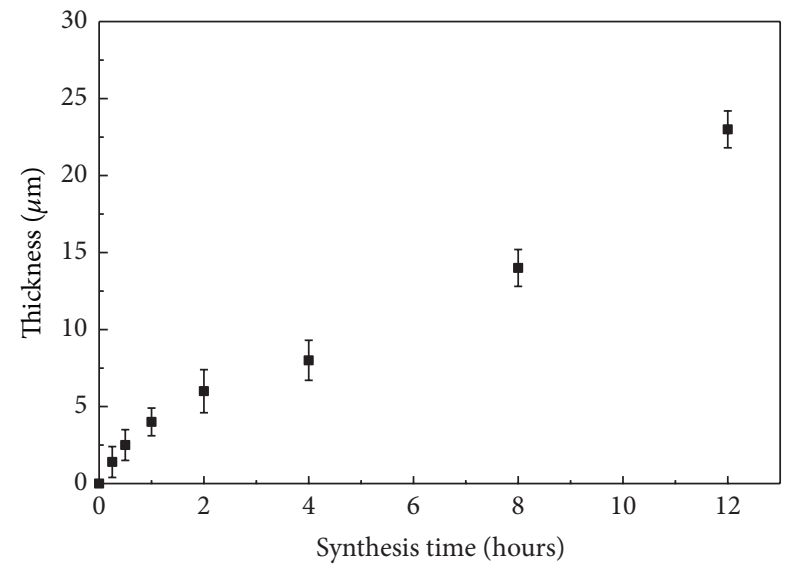

- $\mathrm{T}=90^{\circ} \mathrm{C}$

FIGURE 3: Measured relationship of structure thickness versus synthesis time.

and the sea-urchin-like structure becomes more obvious. As the length of the sea-urchin-like structure increases, the effective total surface area of the photoanode also increases, thus enhancing dye absorbance.

Figure 3 depicts the measured relationship of the thickness of the structure versus the synthesis time. A longer deposition time resulted in a thicker nanostructure. The thickness of the synthesized structure increased from 0 to about $25 \mu \mathrm{m}$ within $12 \mathrm{~h}$. During the early stage of the synthesis process (synthesis time is less than 4 hours), the $\mathrm{ZnO}$ particles are relatively small and the branches on each $\mathrm{ZnO}$ particle are relatively thin and short. These particles closely pile up to form a $\mathrm{ZnO}$ film. However, as the synthesis time is larger than 4 hours, the $\mathrm{ZnO}$ particles become larger and the branches of each $\mathrm{ZnO}$ particle become thicker and longer (i.e., stronger). These bigger $\mathrm{ZnO}$ particles are relatively difficult to be closely packed and stacked. As a result, these bigger particles with stronger branches uphold the film structure, and the density of the film becomes smaller, as compared with the film formed by smaller particles. Therefore, the film thickness increases faster as the synthesis time is larger than 4 hours.

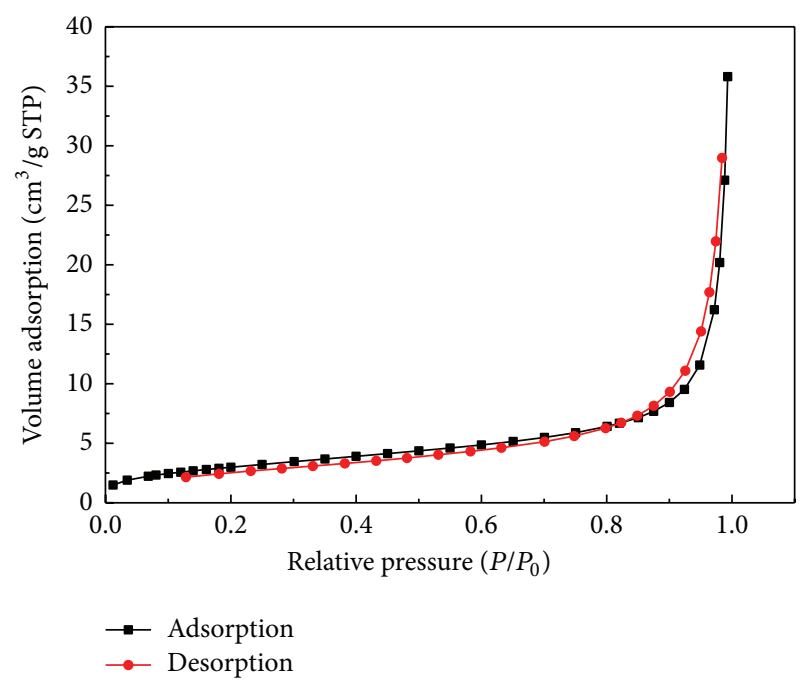

Figure 4: Typical $\mathrm{N}_{2}$ adsorption-desorption isotherms for the seaurchin-like $\mathrm{ZnO}$ film.

As shown in Figures 2(a) and 2(b), the $\mathrm{ZnO}$ film of 4hour synthesis is more packed than the $\mathrm{ZnO}$ film of 8-hour synthesis.

The specific surface area and average internal pore morphology of the sea-urchin-like $\mathrm{ZnO}$ nanoparticle film were obtained by analyzing nitrogen adsorption and desorption isotherms (Figure 4). According to the results, the seaurchin-like $\mathrm{ZnO}$ film can be categorized as a general Type III isotherm that exhibits no hysteresis. The isotherms indicated that nitrogen adsorption and desorption occur predominantly at $P / P_{0}>0.8$. Figure 5 shows the results of the pore size analysis conducted using the Barrett, Joyner, and Halenda (BJH) method. The specific surface area was calculated using the standard Brunauer-Emmett-Teller (BET) analysis of the adsorption isotherms and was estimated at about $11.09 \mathrm{~m}^{2} / \mathrm{g}$. The surface area-to-volume ratio from this analysis implied an average pore diameter of about $198.8 \AA$.

The crystal orientation of the sea-urchin-like $\mathrm{ZnO}$ nanoparticles structure was characterized using X-ray diffraction (Rigaku TTRAX 3) (Figure 6). The diffraction 


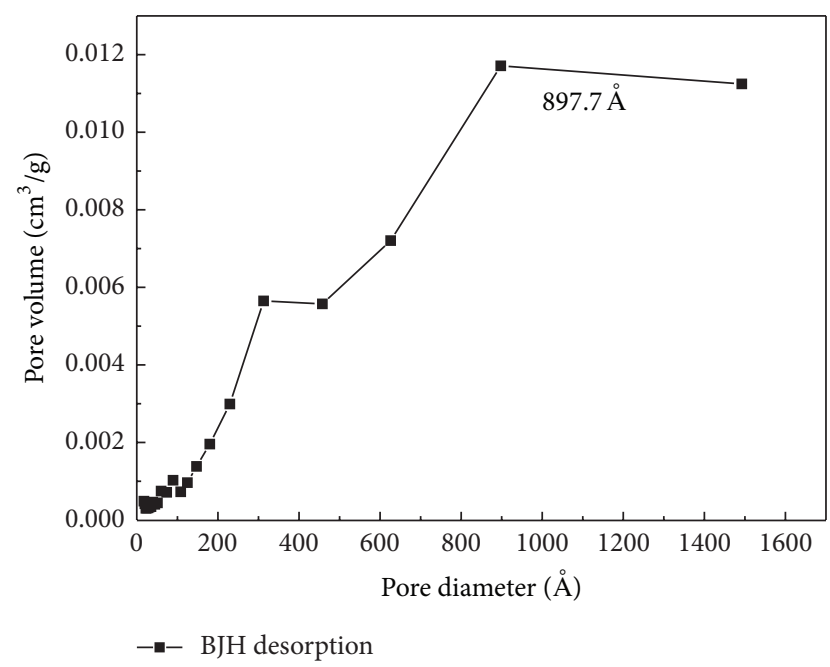

FIGURE 5: BJH pore diameter distribution curve.

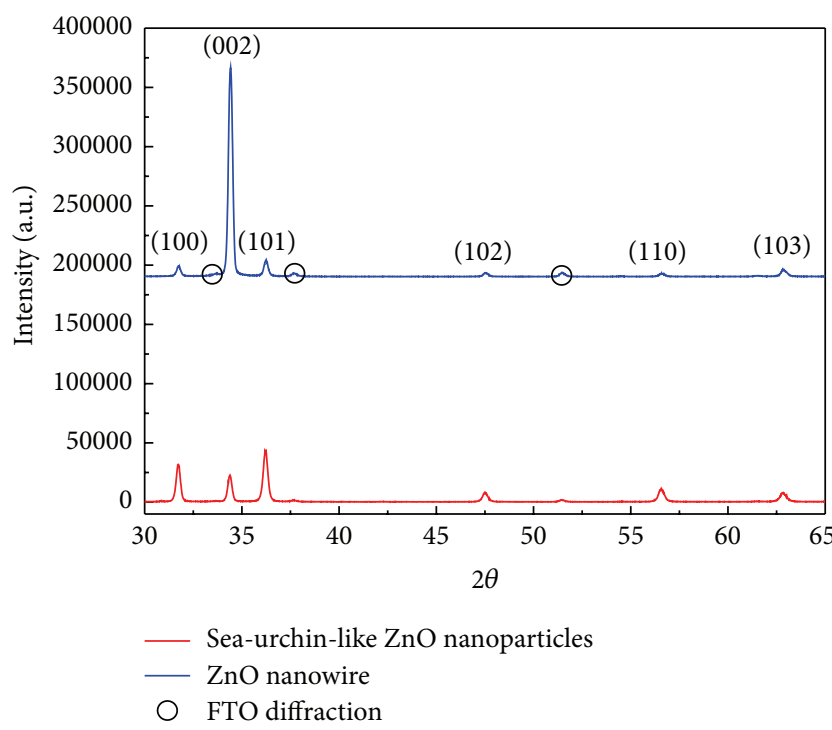

FIGURE 6: XRD patterns of sea-urchin-like $\mathrm{ZnO}$ nanoparticles and $\mathrm{ZnO}$ nanowires.

peaks can be indexed as a hexagonal wurtzite $\mathrm{ZnO}$ phase in contrast to JCPDS Card number 75-1526 [21]. Compared with the XRD patterns of typical $\mathrm{ZnO}$ nanowires, the Z-direction (002) intensity of the sea-urchin-like $\mathrm{ZnO}$ nanoparticles was relatively flat, indicating that the orientations of the $\mathrm{ZnO}$ crystal structures in the sea-urchin-like structure are quite random.

3.2. Photocurrent-Voltage and Power Conversion Characteristics. Current-voltage $(I-V)$ curve measurements were conducted using a source meter (Keithley 2410). Simulated AM $1.5 \mathrm{G}\left(100 \mathrm{~mW} / \mathrm{cm}^{2}\right)$ illumination was provided by a solar light source (Newport class A), and the light intensity was measured using a calibrated Si solar cell. The total measurement area of the photoanode was $0.25 \mathrm{~cm}^{2}$, and the voltage swept from -1 to $1 \mathrm{~V}$ in fixed increments of $0.02 \mathrm{~V}$.
TABLE 1: Photovoltaic performance data of the proposed DSSC with different synthesis times.

\begin{tabular}{lcccc}
\hline & $J_{\mathrm{SC}}\left(\mathrm{mA} / \mathrm{cm}^{2}\right)$ & $V_{\mathrm{OC}}(\mathrm{V})$ & $\mathrm{FF}$ & $\eta(\%)$ \\
\hline $2 \mathrm{hrs}$ & 3.37 & 0.45 & 53.85 & 0.81 \\
$4 \mathrm{hrs}$ & 4.01 & 0.49 & 58.00 & 1.14 \\
$8 \mathrm{hrs}$ & 4.70 & 0.59 & 50.19 & 1.16 \\
$16 \mathrm{hrs}$ & 1.24 & 0.33 & 70.87 & 0.29 \\
\hline
\end{tabular}

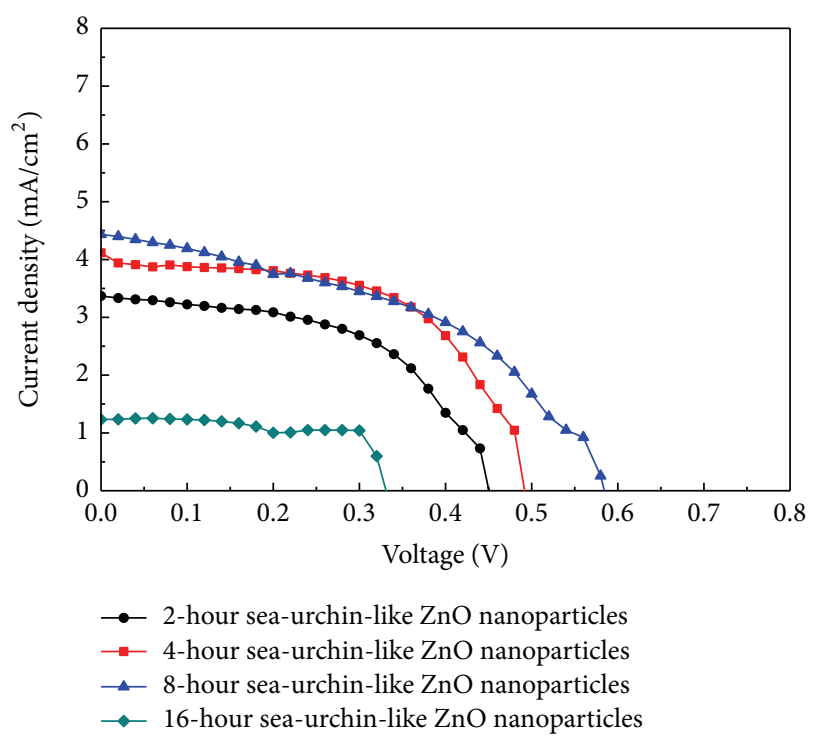

FIGURE 7: $I-V$ characteristic curve of the proposed DSSC.

Figure 7 illustrates the $I-V$ characteristics of the seaurchin-like $\mathrm{ZnO}$ nanoparticles with dissimilar deposition times. The longer the deposition time was, the higher the photocurrent was. Notably, at a deposition time of $16 \mathrm{~h}$, the photocurrent became extremely low, possibly because overdeposited nanoparticles caused the electron transport pathway to become excessively long, thus substantially reducing the power conversion efficiency. The maximum conversion efficiency was approximately $1.16 \%$. The corresponding photovoltaic parameters are summarized in Table 1.

Incident photo-to-current efficiency (IPCE) spectrum measurements were also conducted using a $300 \mathrm{~W}$ xenon lamp and a grating monochromator. In the measurement, the wavelength ranged from 400 to $800 \mathrm{~nm}$ with a spectral resolution of $20 \mathrm{~nm}$. The samples fabricated at various deposition times were measured. Figure 8 depicts the results of the IPCE characteristics for different sea-urchin-like $\mathrm{ZnO}$ nanoparticles. The results are similar to the adsorption spectrum of N719 dye [22]. In the current study, the highest IPCE value was $15.32 \%$.

The impedance and phase were measured under an illumination of $100 \mathrm{~mW} / \mathrm{cm}^{2}$. The AC signal parameter was $10 \mathrm{mV}$, and the scanning range was from 105 to $0.05 \mathrm{~Hz}$. The measured samples were the same as those used in the IPCE measurement. Figure 9 shows the Nyquist plot of two sea-urchin-like $\mathrm{ZnO}$ nanoparticles fabricated using different deposition times. Table 2 lists the derived circuit parameters 
TABLE 2: Summary of derived circuit parameters: the impedance of transport resistance of the electrons in $\mathrm{ZnO}\left(R_{t}\right)$, charge transfer resistance of charge recombination process $\left(R_{\mathrm{ct}}\right)$, electron lifetime $(\tau)$, chemical capacitance of the $\mathrm{ZnO}\left(C_{\mu}\right)$, electron diffusion coefficient in $\mathrm{ZnO}(D)$, and effective diffusion length $\left(L_{n}\right)$.

\begin{tabular}{lccccccc}
\hline Cell & $f_{\max , m}\left(\mathrm{~s}^{-1}\right)$ & $\tau(\mathrm{ms})$ & $R_{\mathrm{ct}}(\Omega)$ & $R_{t}(\Omega)$ & $C_{\mu}(\mu \mathrm{F})$ & $D\left(\mathrm{~cm}^{2} / \mathrm{s}\right)$ & $L_{n}(\mu \mathrm{m})$ \\
\hline $2 \mathrm{hrs}$ & 1.28 & 124 & 2247 & 608.3 & 55.4 & $1.186 \times 10^{-4}$ \\
$8 \mathrm{hrs}$ & 3.17 & 50.1 & 2736 & 1059 & 18.3 & $2.06 \times 10^{-4}$ \\
\hline
\end{tabular}

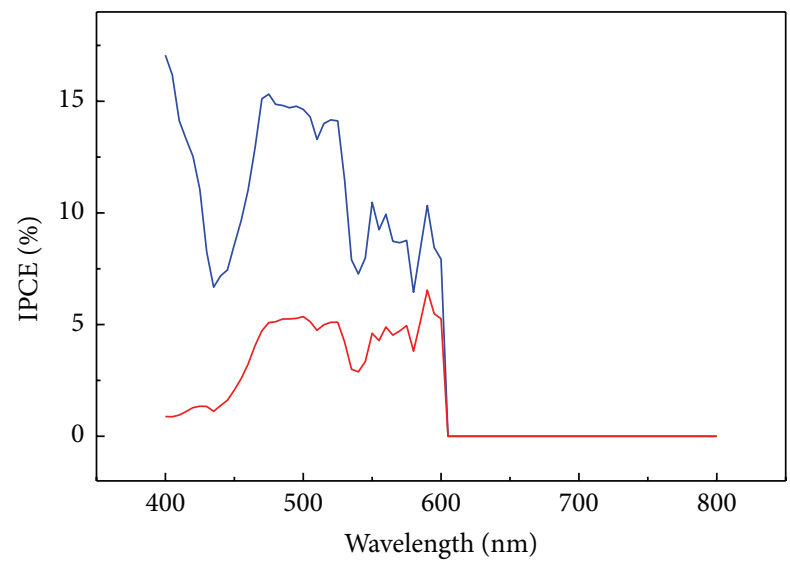

- Sea-urchin-like $\mathrm{ZnO}$ nanoparticles with $8 \mathrm{hrs}$

_ Sea-urchin-like $\mathrm{ZnO}$ nanoparticles with $2 \mathrm{hrs}$

FIGURE 8: IPCE spectra of the proposed DSSCs.

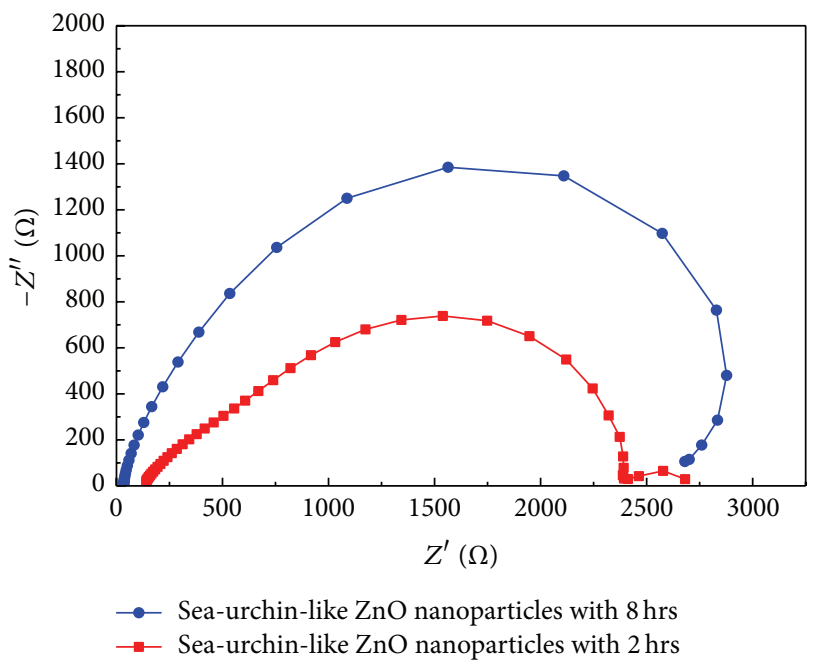

FIGURE 9: Nyquist plot of the proposed DSSC with different synthesis times.

after the data were fitted using a proper equivalent circuit model [23]. The results indicated that a thicker photoanode resulted in a higher electron transport resistance $\left(R_{t}\right)$ and a higher charge transfer resistance of the charge recombination process $\left(R_{\mathrm{ct}}\right)$. The lifetime $(\tau)$ of injected electrons in the $\mathrm{ZnO}$ nanoparticles is defined as $\tau=1 / 2 \pi f$. According to the EIS model, the frequency $f$ can be extracted using the position of the medium-frequency peak shown in Figure 6, where $f$ is the medium-frequency peak [24]. This figure also shows that thicker photoanodes provide a longer electron lifetime.

\section{Conclusion}

In this study, we developed novel photoanode material architecture based on sea-urchin-like $\mathrm{ZnO}$ nanoparticles and integrated it into a DSSC system. Nanoparticles were synthesized using a simple chemical solution method. The effect of the reaction parameters on the $\mathrm{ZnO}$ nanostructure morphology was also studied. BET analysis of the adsorption isotherms was employed to estimate the specific surface area at approximately $11.09 \mathrm{~m}^{2} / \mathrm{g}$. In addition, the XRD patterns of the $\mathrm{ZnO}$ film showed strong intensity in every direction, indicating that the orientations of the $\mathrm{ZnO}$ nanostructures are randomly distributed. The sample synthesized using a deposition time of $8 \mathrm{~h}$ exhibited a high power conversion efficiency of approximately $1.16 \%$ and an IPCE efficiency of approximately $15.32 \%$. The characteristics of DSSCs measured using electrochemical impedance spectroscopy are also presented.

\section{Conflict of Interests}

The authors declare that there is no conflict of interests regarding the publication of this paper.

\section{Acknowledgment}

This work was supported in part by the National Science Council, Taiwan (Contract no. NSC 100-2221-E-002-074MY3).

\section{References}

[1] M. Grätzel, "Photoelectrochemical cells," Nature, vol. 414, no. 6861, pp. 338-344, 2001.

[2] S. Gubbala, V. Chakrapani, V. Kumar, and M. K. Sunkara, "Band-edge engineered hybrid structures for dye-sensitized solar cells based on $\mathrm{SnO}_{2}$ nanowires," Advanced Functional Materials, vol. 18, no. 16, pp. 2411-2418, 2008.

[3] G. K. Mor, K. Shankar, M. Paulose, O. K. Varghese, and C. A. Grimes, "Use of highly-ordered $\mathrm{TiO}_{2}$ nanotube arrays in dyesensitized solar cells," Nano Letters, vol. 6, no. 2, pp. 215-218, 2006.

[4] B. O’Regan and M. Grätzel, "A low-cost, high-efficiency solar cell based on dye-sensitized colloidal $\mathrm{TiO}_{2}$ films," Nature, vol. 353, no. 6346, pp. 737-740, 1991.

[5] Y. G. Seo, K. Woo, J. Kim, H. Lee, and W. Lee, "Rapid fabrication of an inverse opal $\mathrm{TiO}_{2}$ photoelectrode for DSSC using a binary mixture of $\mathrm{TiO}_{2}$ nanoparticles and polymer microspheres," Advanced Functional Materials, vol. 21, no. 16, pp. 3094-3103, 2011. 
[6] E. S. Kwak, W. Lee, N.-C. Park, J. Kim, and H. Lee, "Compact inverse-opal electrode using non-aggregated $\mathrm{TiO}_{2}$ nanoparticles for dye-sensitized solar cells," Advanced Functional Materials, vol. 19, no. 7, pp. 1093-1099, 2009.

[7] B. Liu and E. S. Aydil, "Growth of oriented single-crystalline rutile $\mathrm{TiO}_{2}$ nanorods on transparent conducting substrates for dye-sensitized solar cells," Journal of the American Chemical Society, vol. 131, no. 11, pp. 3985-3990, 2009.

[8] X. Feng, K. Shankar, O. K. Varghese, M. Paulose, T. J. Latempa, and C. A. Grimes, "Vertically aligned single crystal $\mathrm{TiO}_{2}$ nanowire arrays grown directly on transparent conducting oxide coated glass: synthesis details and applications," Nano Letters, vol. 8, no. 11, pp. 3781-3786, 2008.

[9] G. Yang, C. Miao, Z. Bu, Q. Wang, and W. Guo, "Seed free and low temperature growth of $\mathrm{ZnO}$ nanowires in mesoporous $\mathrm{TiO}_{2}$ film for dye-sensitized solar cells with enhanced photovoltaic performance," Journal of Power Sources, vol. 233, pp. 74-78, 2013.

[10] K. Zhu, T. B. Vinzant, N. R. Neale, and A. J. Frank, "Removing structural disorder from oriented $\mathrm{TiO}_{2}$ nanotube arrays: reducing the dimensionality of transport and recombination in dyesensitized solar cells," Nano Letters, vol. 7, no. 12, pp. 3739-3746, 2007.

[11] Q. Zhang, C. S. Dandeneau, X. Zhou, and C. Cao, "ZnO nanostructures for dye-sensitized solar cells," Advanced Materials, vol. 21, no. 41, pp. 4087-4108, 2009.

[12] C.-X. He, B.-X. Lei, Y.-F. Wang, C.-Y. Su, Y.-P. Fang, and D.-B. Kuang, "Sonochemical preparation of hierarchical $\mathrm{ZnO}$ hollow spheres for efficient dye-sensitized solar cells," Chemistry-A European Journal, vol. 16, no. 29, pp. 8757-8761, 2010.

[13] M. Law, L. E. Greene, J. C. Johnson, R. Saykally, and P. Yang, "Nanowire dye-sensitized solar cells," Nature Materials, vol. 4, no. 6, pp. 455-459, 2005.

[14] A. B. F. Martinson, J. W. Elam, J. T. Hupp, and M. J. Pellin, “ ZnO nanotube based dye-sensitized solar cells," Nano Letters, vol. 7, no. 8, pp. 2183-2187, 2007.

[15] S. H. Ko, D. Lee, H. W. Kang et al., "Nanoforest of hydrothermally grown hierarchical $\mathrm{ZnO}$ nanowires for a high efficiency dye-sensitized solar cell," Nano Letters, vol. 11, no. 2, pp. 666671, 2011.

[16] K. Kakiuchi, M. Saito, and S. Fujihara, "Fabrication of ZnO films consisting of densely accumulated mesoporous nanosheets and their dye-sensitized solar cell performance," Thin Solid Films, vol. 516, no. 8, pp. 2026-2030, 2008.

[17] G.-J. Chang, S.-Y. Lin, and J.-J. Wu, "Room-temperature chemical integration of $\mathrm{ZnO}$ nanoarchitectures on plastic substrates for flexible dye-sensitized solar cells," Nanoscale, vol. 6, no. 3, pp. 1329-1334, 2014.

[18] Y. Shi, K. Wang, Y. Du et al., "Solid-state synthesis of $\mathrm{ZnO}$ nanostructures for quasi-solid dye-sensitized solar cells with high efficiencies up to 6.46\%," Advanced Materials, vol. 25, no. 32, pp. 4413-4419, 2013.

[19] L. Vayssieres, K. Keis, S.-E. Lindquist, and A. Hagfeldt, "Purpose-built anisotropic metal oxide material: $3 \mathrm{~d}$ highly oriented microrod array of $\mathrm{ZnO}$," The Journal of Physical Chemistry B, vol. 105, no. 17, pp. 3350-3352, 2001.

[20] L. Wang, D. Tsan, B. Stoeber, and K. Walus, "Substrate-free fabrication of self-supporting $\mathrm{ZnO}$ nanowire arrays," Advanced Materials, vol. 24, no. 29, pp. 3999-4004, 2012.

[21] P. Yang, H. Yan, S. Mao et al., "Controlled growth of $\mathrm{ZnO}$ nanowires and their optical properties," Advanced Functional Materials, vol. 12, no. 5, pp. 323-331, 2002.
[22] M. K. Nazeeruddin, R. Humphry-Baker, P. Liska, and M. Grätzel, "Investigation of sensitizer adsorption and the influence of protons on current and voltage of a dye-sensitized nanocrystalline $\mathrm{TiO}_{2}$ solar cell," The Journal of Physical Chemistry B, vol. 107, no. 34, pp. 8981-8987, 2003.

[23] M. Adachi, M. Sakamoto, J. Jiu, Y. Ogata, and S. Isoda, "Determination of parameters of electron transport in dye-sensitized solar cells using electrochemical impedance spectroscopy," The Journal of Physical Chemistry B, vol.110, no. 28, pp. 13872-13880, 2006.

[24] R. Kern, R. Sastrawan, J. Ferber, R. Stangl, and J. Luther, "Modeling and interpretation of electrical impedance spectra of dye solar cells operated under open-circuit conditions," Electrochimica Acta, vol. 47, no. 26, pp. 4213-4225, 2002. 

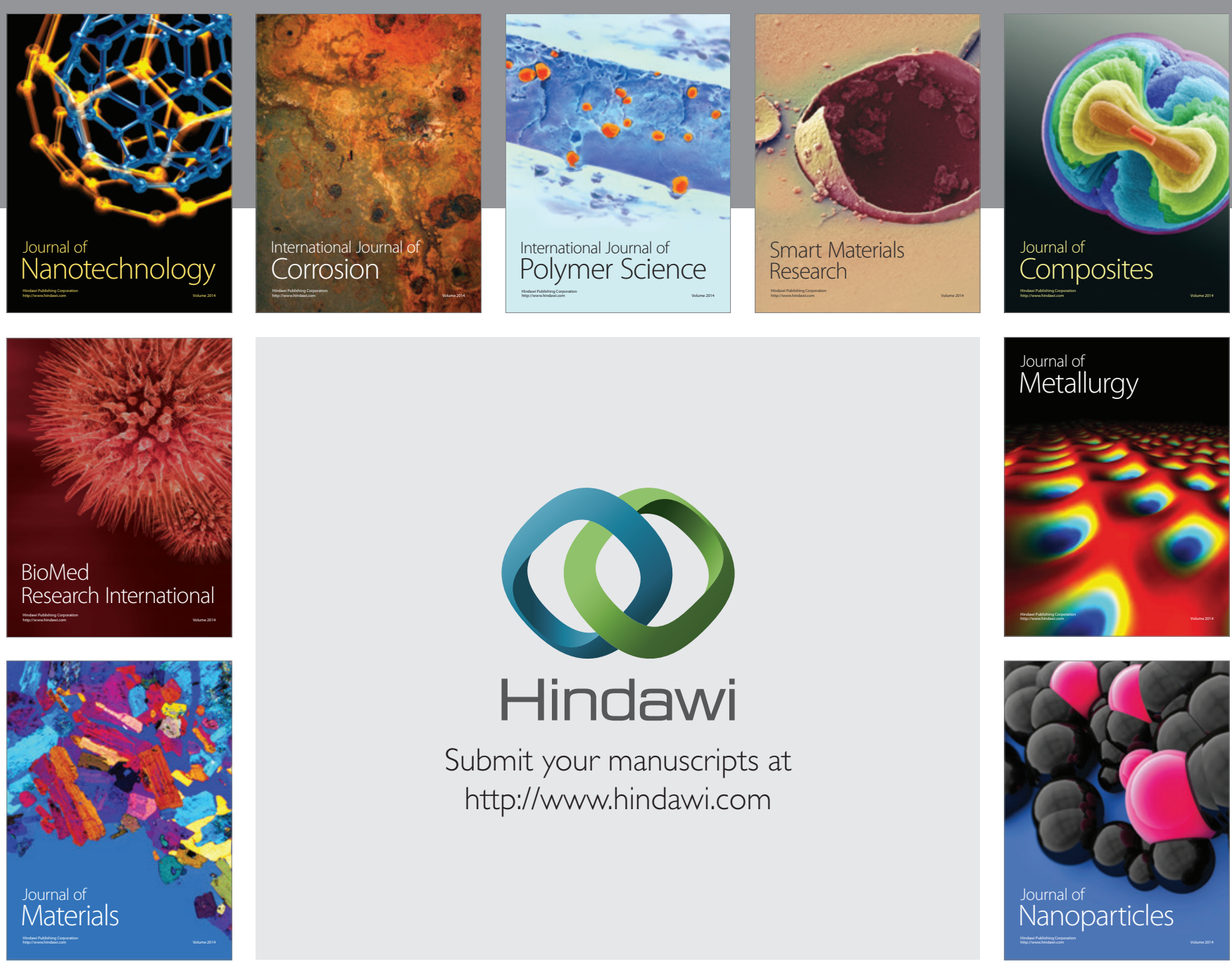

Submit your manuscripts at http://www.hindawi.com
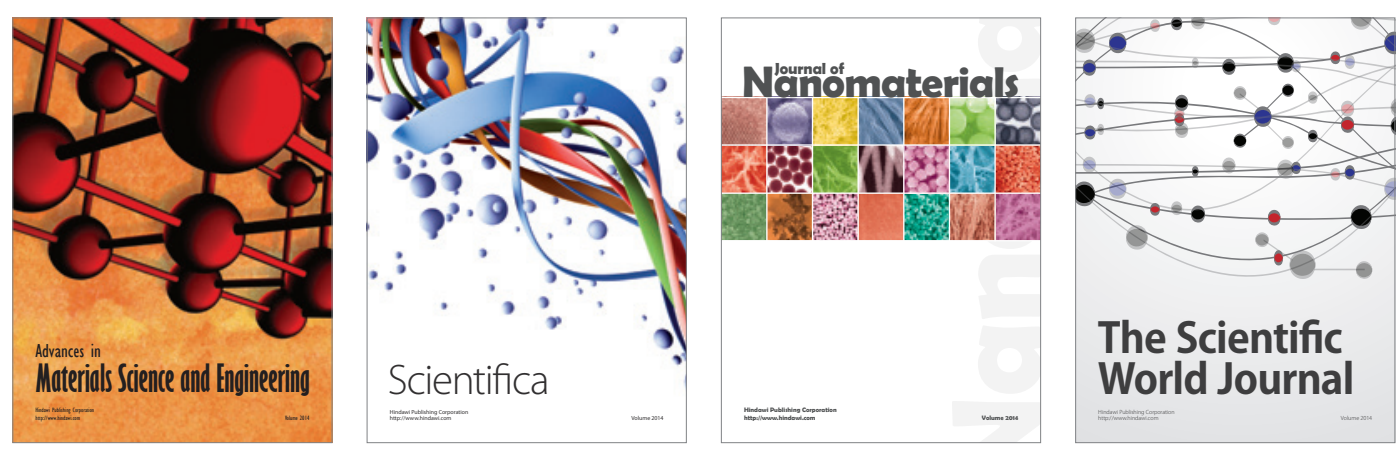

\section{The Scientific World Journal}
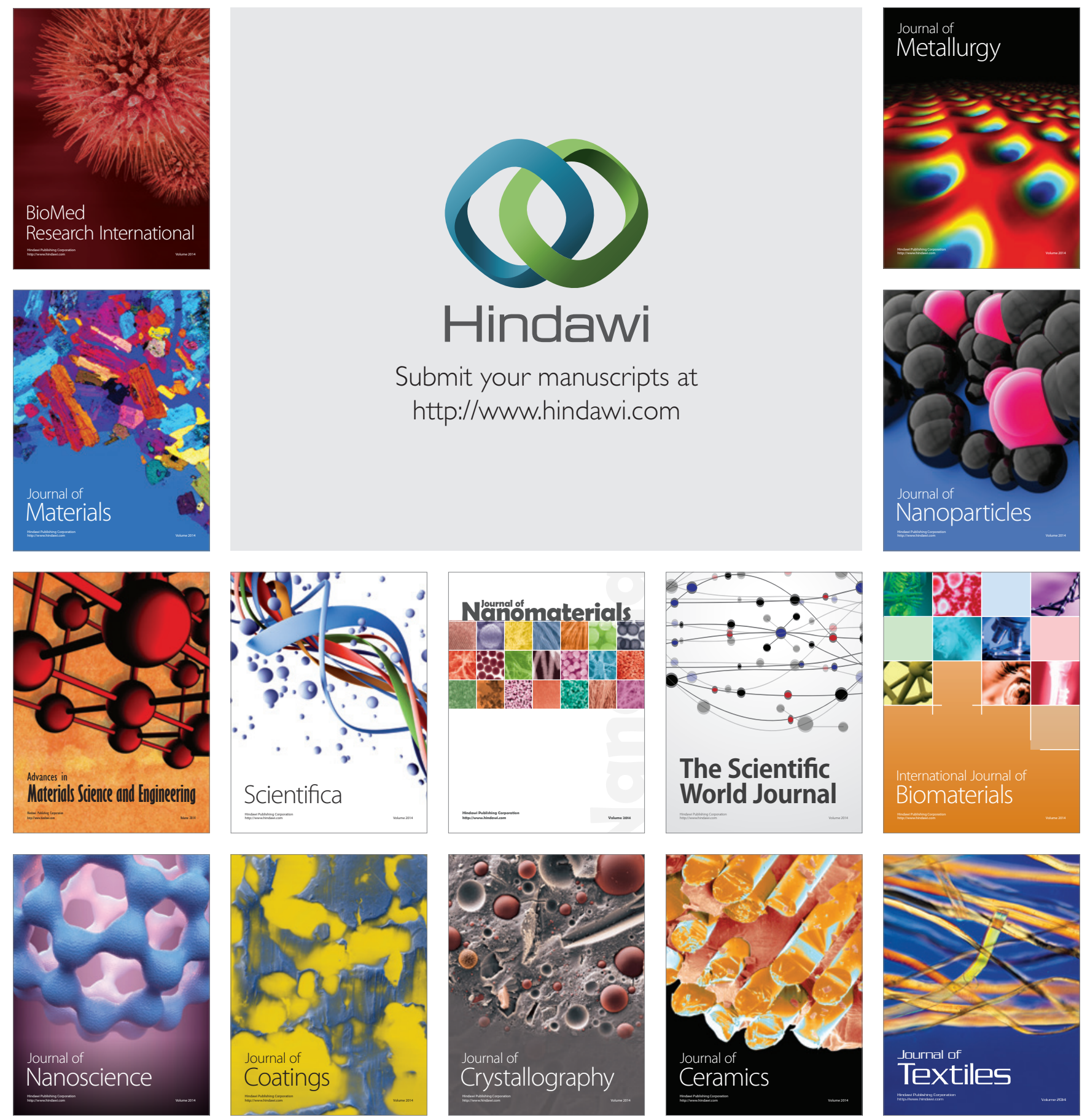